Relations industrielles

Industrial Relations

\title{
Le Conseil Supérieur du Travail
}

Volume 1, numéro 4, décembre 1945

URI : https://id.erudit.org/iderudit/1023917ar

DOI : https://doi.org/10.7202/1023917ar

Aller au sommaire du numéro

Éditeur(s)

Département des relations industrielles de l’Université Laval

ISSN

0034-379X (imprimé)

1703-8138 (numérique)

Découvrir la revue

Citer cet article

(1945). Le Conseil Supérieur du Travail. Relations industrielles / Industrial

Relations, 1(4), 3-3. https://doi.org/10.7202/1023917ar

Tous droits réservés (C Département des relations industrielles de l’Université Laval, 1945
Ce document est protégé par la loi sur le droit d'auteur. L’utilisation des services d'Érudit (y compris la reproduction) est assujettie à sa politique d'utilisation que vous pouvez consulter en ligne.

https://apropos.erudit.org/fr/usagers/politique-dutilisation/ 


\section{LA SANTÉ INDUSTRIELLE}

La santé industrielle n'est pas un état collectif résultant du nombre plus ou moins élevé d'accidents ou de maladies du travail, ou de l'ensemble des mesures de sanitation et de sécurité appliquées dans une industrie particulière. Elle est la résultante des divers facteurs qui, dans chacune des manifestations de la vie ouvrière (travail, alimentation, habitation, loisirs mêmes), réagissent sur l'état physique et mental du travailleur, et dans la même mesure sur la qualité et la quantité de son travail.

La santé industrielle se manifeste par le rendement industriel de l'ouvrier en fonction de sa santé propre. "La santé de l'ouvrier est le facteur industriel le plus important ". Cette déclaration n'est pas de nous ni d'un autre médecin, mais elle nous vient conjointement et en droite ligne des grands maitres de l'industrie : Malcolm MacDonald, Commissaire du Royaume-Uni (Their Health is a Matter of Crucial Importance, 1942) et des chefs de la National Manufacturers Association.

Or la santé du travailleur est un état à la détérioration duquel le facteur industriel, ou le travail même, concourt proportionnellement peu. C. D. Selby (in : Industrial Health, 1939) fait remarquer que l'ouvrier consacre un peu moins de $25 \%$ des heures d'une année à son travail même, et que cependant $94 \%$ de sa période d'incapacité totale annuelle, ou de son absence au travail, est dâ à des états de santé auxquels le facteur industriel est complètement étranger.

Les rapports de la Ligue de Santé du Canada établissent qu'en 1942 l'ouvrier canadien a perdu en moyenne neuf jours et demi de travail se répartissant comme suit : une demi-journée par accident du travail ou maladie professionnelle et neuf jours par maladies ou accidents non causés par le travail. Notons en passant que ces neuf jours ont représenté une perte de cinquante millions de dollars pour l'ouvrier canadien en 1942. La perte des industriels s'évalue, d'après les Public Health Reports de K. Brundage, à une fois et demie les gages perdus ; ce fut donc pour l'industrie canadienne une perte de $\$ 125,000,000.00$ (cent vingt-cinq millions de dollars) causee par des maladies ou des accidents non professionnels.

D'après C. O. Sappington (in : Industrial Health, 1943) dix pour cent des cas d'absence au travail par incapacité physique temporaire sont dus à des accidents ou à des maladies rattachables au travail lui-même, et quatre-vingt-dix pour cent des absences sont dues à des états de santé qui n'ont aucune relation avec le travail de l'ouvrier à l'usine ou au chantier. En somme, le manque-à-gagner de l'ouvrier par suite de son état de santé physique provient de facteurs qui ont relativement peu à voir avec l'existence et le fonctionnement de l'établissement industriel où il exerce son métier ; et si la médecine industrielle doit réaliser son but, qui est d'assurer au travailleur le meilleur rendement, et le plus longtemps possible, par une meilleure santé, elle doit donc maintenir, développer et protéger cette santé non seulement à l'usine, mais encore dans le milieu social, dans le milieu familial et même dans les phases récréatives de la vie du travailleur.

Tel doit être le principe fondamental d'un service de santé industrielle.

Docteur Wilfrid LeBlond, chargé du cours d'Hygiène industrielle à l'Université Laval, Québec.

\section{LE CONSEIL SUPÉRIEUR DU TRAVAIL}

Sans compromettre son autorité, un gouvernement démocratique a le devoir de consulter les organismes professionnels qui peuvent le conseiller et lui suggérer les voies à suivre. C'est ainsi que, progressivement, les syndicats ouvriers et les associations patronales participent aux fonctions gouvernementales, soit parce qu'ils sont consultés en tant qu'ils font partie d'organismes publics ou semi-publics, soit parce qu'ils participent directement au pouvoir réglementaire.

Dans la province de Québec, les associations professionnelles, patronales et ouvrières, participent aux fonctions gouvernementales par l'intermédiaire du Conseil supérieur du Travail qui a pour mission d'étudier les questions relatives à la protection des salariés, à la rationalisation du travail, aux conventions collectives, aux salaires minima, à l'apprentissage, à l'orientation professionnelle, à l'assurance et à l'assistance sociales, etc. En nombre égal, les représentants patronaux et ouvriers sont désignés par les associations les plus représentatives auxquels se joignent un groupe d'économistes et de sociologues. Une commission permanente sert de lien entre le Conseil supérieur et le Ministère du Travail. Les recommandations du Conseil n'ont pas un caractère obligatoire, mais elles influencent l'évolution de la législation. Depuis quatre ans, le Conseil supérieur du Travail a guidé le développement de nos lois ouvrières tandis que son secrétariat a préparé des études documentaires et techniques de première valeur. Le Conseil est un organisme officiel que doivent appuyer tous les syndicats ouvriers et les employeurs. 